\title{
Microstructure Analysis and Optimization of Sputter-Deposited Zinc Oxide Thin Films Used in Low-Emissivity Coatings for Energy Efficient Windows
}

\author{
Kazuhiro Kato, Hideo Omoto and Atsushi Takamatsu \\ Glass Research Center, Central Glass Co., Ltd., 1510 Ohkuchi-cho, Matsusaka-city, Mie Pref. \\ Fax: 81-598-53-3180, e-mail: kazuhiro.kato@cgco.co.jp
}

\begin{abstract}
$\mathrm{ZnO}$ thin films were deposited with changing oxygen gas pressure and their microstructures were investigated by the glancing incident X-ray reflectivity measurement. It was found that the $\mathrm{ZnO}$ thin films exhibited higher packing density and smoother surface morphology, when they were deposited in lower oxygen gas pressure. These microstructure improvements of $\mathrm{ZnO}$ thin films with decreasing in oxygen gas pressure should come from the increase in the kinetic energy of sputtered $\mathrm{Zn}$ atoms and gas particles such as oxygen negative ions recoiled from the sputtering target surface. Furthermore, the double-layered low-emissivity coatings consisting of glass/ $\mathrm{ZnO} / \mathrm{Ag}$ were also prepared and the correlation between the microstructure of $\mathrm{ZnO}$ thin films and the electrical property of the Ag thin films was clarified. The Ag thin films exhibited low electrical resistivity when the $\mathrm{ZnO}$ thin films deposited in low oxygen gas pressure were used. It can be considered that this improvement in the Ag resistivity is attribute to the high packing density and smooth surface of the $\mathrm{ZnO}$ thin film.
\end{abstract}

Key words: Ag, low-emissivity coating, packing density, sputtering, $\mathrm{ZnO}$

\section{INTRODUCTION}

Insulating glass units constructed of a pair of glass panes are used as energy efficient windows for buildings. Besides, low-emissivity (low-e) coatings are often deposited on one side of the glass panes by magnetron sputtering to improve thermal emission and solar reflectance toward outside room $[1,2]$. Since Ag exhibits lowest electrical resistivity and emissivity in infrared light among of all metals, the low-e coatings are usually consisting of the Ag-based multilayer, such as glass/under-dielectric/Ag/over-dielectric or the repetition structure, moreover, $\mathrm{ZnO}$-based thin films are often used as the dielectrics. Nowadays, the low-e coatings are required to exhibit not only high solar energy reflectance but also high visible light transmittance. However, the low-e coating which exhibits both performances has not been available yet, because the Ag thin films used in low-e coatings exhibit much higher resistivity than the bulk Ag; therefore, that leads to a decrease in solar reflectance per unit Ag thickness [3]. It has been reported that the sputtering deposition conditions for Ag thin films, such as cathode voltage [4], pulse frequency applied to sputtering target [5], substrate bias voltage [6], gas pressure [7] and gas component [8,9], influence the resistivity of Ag thin films. Moreover, previous studies have revealed that the resistivity of the Ag thin films used in the low-e coatings strongly depends on the microstructures and compounds of under-dielectrics such as $\mathrm{ZnO}$, Al-doped $\mathrm{ZnO}$ and $\mathrm{SnO}_{2}$ [10-12]. However, the optimum microstructures of under-dielectrics to obtain low-resistive Ag thin film used in low-e coatings have not fully been clarified yet. In this paper, we present the microstructures of $\mathrm{ZnO}$ thin films as a function of oxygen gas pressure during the sputtering deposition. Besides, the correlation between oxygen gas pressure and microstructures of the $\mathrm{ZnO}$ thin films is discussed. Furthermore, double-layered low-e coatings such as glass/ $\mathrm{ZnO} / \mathrm{Ag}$ were prepared using the $\mathrm{ZnO}$ under layers deposited in various oxygen gas pressure. Here, the over-dielectrics were not coated on the Ag layers in order to avoid the complication. Then, the optimum microstructures of $\mathrm{ZnO}$ under layers used in low-e coatings are suggested on the basis of the microstructure analysis.

\section{EXPERIMENTAL}

All thin films were deposited on soda-lime-silicate glass substrates at room temperature by dc magnetron sputtering. $\mathrm{ZnO}$ single layers with the thickness of about $125 \mathrm{~nm}$ were deposited using a $\mathrm{Zn}$ pure metal target; the applied power was $100 \mathrm{~W}$; oxygen gas pressure was varied from 0.2 to $3.0 \mathrm{~Pa}$. Low-e coatings with a layer construction of glass/ $\mathrm{ZnO} / \mathrm{Ag}$ were deposited; the deposition conditions of $\mathrm{ZnO}$ under layers correspond to those of $\mathrm{ZnO}$ single layers. The 10-nm-thick Ag thin films were deposited 
with $0.5 \mathrm{~Pa}$ argon gas and pure $\mathrm{Ag}$ target; the applied power was $50 \mathrm{~W}$. Each layer with the designed thickness in the low-e coatings was deposited adjusting the deposition time.

X-ray diffraction (XRD, using $\mathrm{CuK} \alpha$ radiation) measurement with out-of-plane arrangement was carried out to evaluate the crystal structure of $\mathrm{ZnO}$ thin films. Glancing incident X-ray reflectivity (GIXR) measurement was performed to evaluate the packing density and surface roughness (Rms) of the $\mathrm{ZnO}$ thin films [13]. The relative packing density (RPD) was calculated using the following equation:

$$
\mathrm{RPD}=\frac{\text { Measured packing density }\left(\mathrm{g} / \mathrm{cm}^{3}\right)}{\text { Maximum packing density }\left(\mathrm{g} / \mathrm{cm}^{3}\right)}
$$

where the maximum packing density means maximum value estimated in the GIXR measurement for $\mathrm{ZnO}$ thin films. Surface morphology of $\mathrm{ZnO}$ thin films was observed with an atomic force microscope (AFM) in a dynamic scan mode. Average surface roughness (Ra) was calculated analyzing the AFM results. Sheet resistance of the low-e coatings was measured by a four-probe method to estimate the resistivity of Ag thin films in the low-e coatings.

\section{RESULTS AND DISCUSSION}

\section{$3.1 \mathrm{ZnO}$ single layer}

Figure 1 shows the XRD patterns of $\mathrm{ZnO}$ thin films deposited in various oxygen gas pressure. It can be seen from Fig. 1 that when the $\mathrm{ZnO}$ thin films were deposited in low gas pressure, the well-crystallized and preferentially oriented $\mathrm{ZnO}$ thin films were obtained; furthermore, the diffraction peak clearly shifted to low angle. This change in the diffraction angle indicates that the $\mathrm{ZnO}$ thin films were compressively distorted with the decrease of the oxygen gas pressure. The relative packing density and surface roughness of

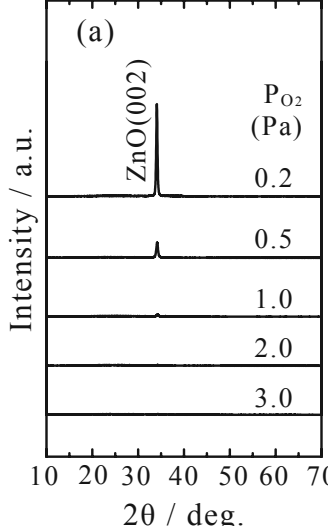

$2 \theta /$ deg.

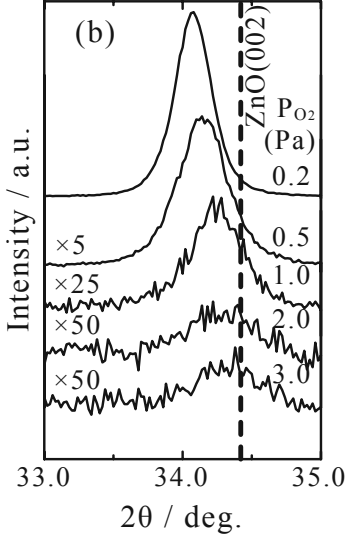

Fig. 1. XRD patterns of $\mathrm{ZnO}$ thin films deposited in various oxygen gas pressure $\left(\mathrm{P}_{\mathrm{O}_{2}}\right)$, where (b) is magnification of (a).

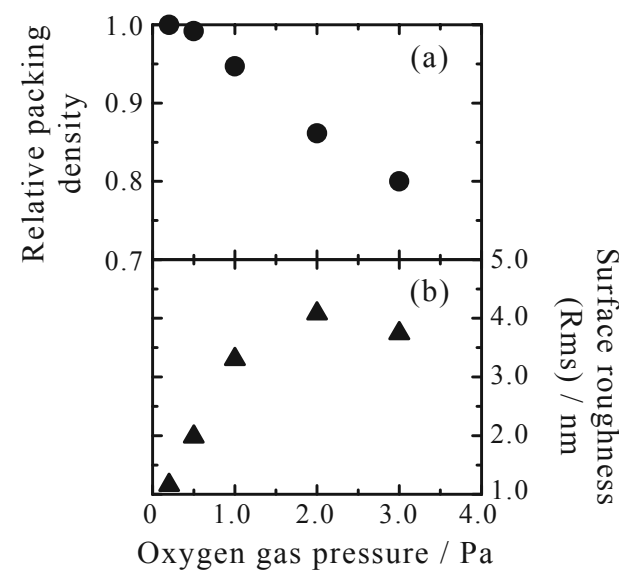

Fig. 2. (a) Relative packing density and (b) surface roughness (Rms) of $\mathrm{ZnO}$ thin films deposited in various oxygen gas pressure.

$\mathrm{ZnO}$ thin films were estimated from the GIXR results and they are represented as a function of oxygen gas pressure in Fig. 2. It was found from Fig. 2 that the packing density of $\mathrm{ZnO}$ thin films systematically increased with decreasing the oxygen gas pressure; moreover, the $\mathrm{ZnO}$ deposited in low oxygen gas pressure exhibited smooth surface. The AFM images of the $\mathrm{ZnO}$ thin films are demonstrated in Fig. 3. It was confirmed from Fig. 3 that the surface of $\mathrm{ZnO}$ thin films became smooth as oxygen gas pressure was decreased. This surface morphology change of $\mathrm{ZnO}$ thin films agreed well with the GIXR results. Besides, a clear relationship between the crystal grain size of $\mathrm{ZnO}$ thin films and oxygen gas pressure was not confirmed.
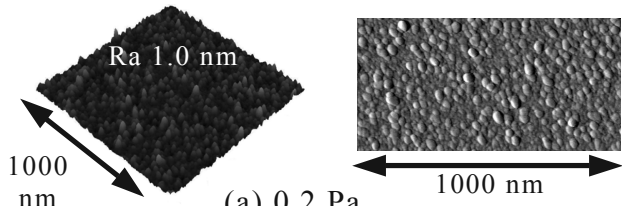

(a) $0.2 \mathrm{~Pa}$

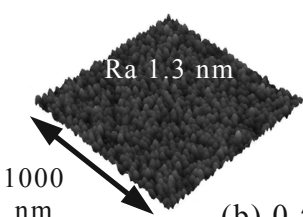

(b) $0.5 \mathrm{~Pa}$
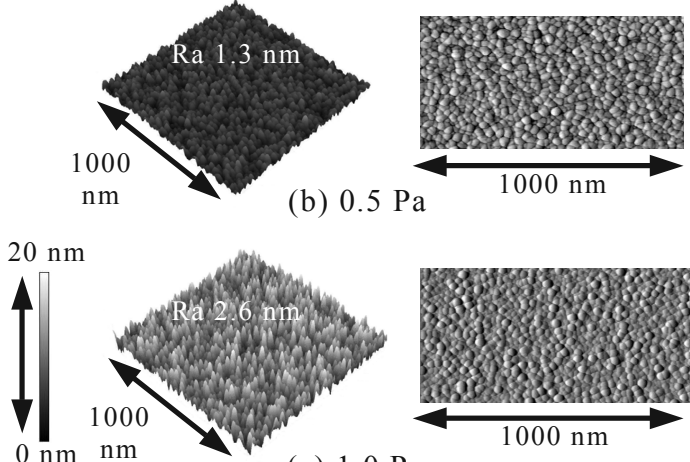

(c) $1.0 \mathrm{~Pa}$

Fig. 3. AFM images of $\mathrm{ZnO}$ thin films deposited in various oxygen gas pressure of (a) 0.2 , (b) 0.5 and (c) $1.0 \mathrm{~Pa}$. 
It is known that cathode voltage biased to a sputtering target during sputtering deposition is one of the dominant parameters to determine the thin film properties and microstructures [14], because the kinetic energy of oxygen negative ions recoiled from the sputtering target depends on the cathode voltage. The cathode voltage supplied to the $\mathrm{Zn}$ target in the $\mathrm{ZnO}$ thin film deposition is plotted in Fig. 4 as a function of oxygen gas pressure. It can be seen in Fig. 4 that the cathode voltage showed almost constant value against oxygen gas pressure, furthermore, a clear relationship was not observed between the cathode voltage and oxygen gas pressure. It can be considered from this result that the microstructure improvement of the $\mathrm{ZnO}$ thin films deposited in low oxygen gas pressure is not due to the change in cathode voltage.

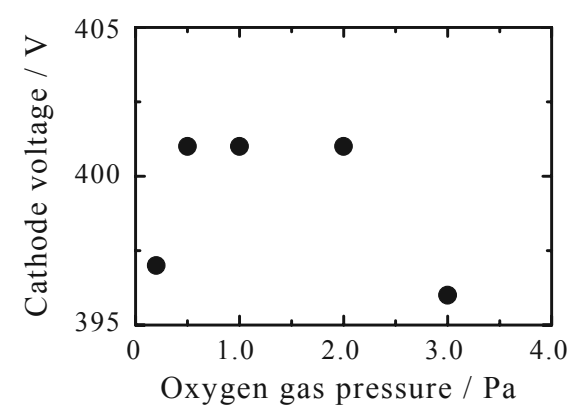

Fig. 4. Dependence of cathode voltage on oxygen gas pressure during $\mathrm{ZnO}$ sputtering deposition.

Besides, it has been reported that the kinetic energy of the particles, such as oxygen negative ions and sputtered atoms, depends on the collision frequency among the oxygen gas molecules, oxygen negative ions and sputtered atoms $[15,16]$. In order to clarify the influence of oxygen gas pressure on the collision frequency and kinetic energy of gas particles, the kinetic energy of oxygen negative ion and sputtered $\mathrm{Zn}$ atom were estimated using Kevin-Meyer's equation given as follows [15-17]:

$$
\mathrm{Ef}=(\mathrm{Ei}-\mathrm{kT}) \exp \left[\mathrm{N} \ln \left(\frac{\mathrm{Ef}}{\mathrm{Ei}}\right)\right]+\mathrm{kT},
$$

where Ef is the kinetic energies of the oxygen negative ion and sputtered $\mathrm{Zn}$ atom reaching at substrate surface. The initial kinetic energy of those particles are represented by Ei, which are assumed to be $400 \mathrm{eV}$ for oxygen negative ion and $3 \mathrm{eV}$ for sputtered $\mathrm{Zn}$ atom. Here, the Ei of oxygen negative ion corresponds to the cathode voltage during $\mathrm{ZnO}$ thin film deposition. The terms of $\mathrm{k}$ and $\mathrm{T}$ are Boltzmann constant and gas temperature, respectively. The collision number is expressed with N, which can be described as follows:

$$
\mathrm{N}=\left(\frac{\mathrm{dp} \sigma}{\mathrm{kT}}\right)
$$

where $\mathrm{d}$ is the distance between the substrate and sputtering target. The terms of $p$ and $\sigma$ are oxygen gas pressure and collision cross section of oxygen gas,

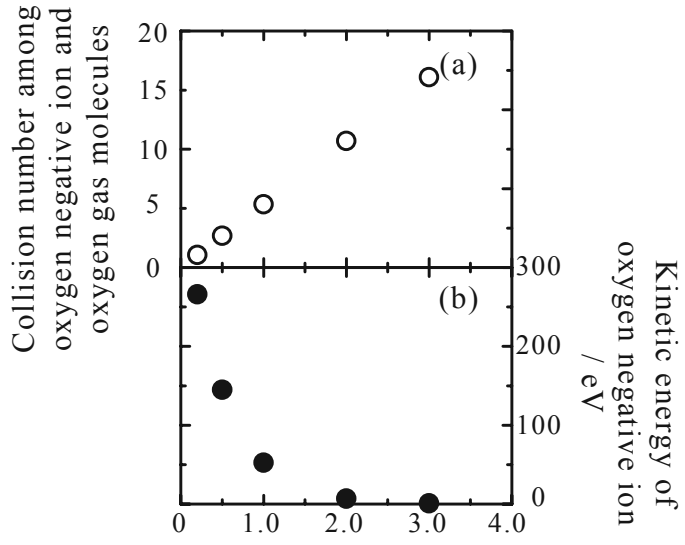

Oxygen gas pressure / $\mathrm{Pa}$

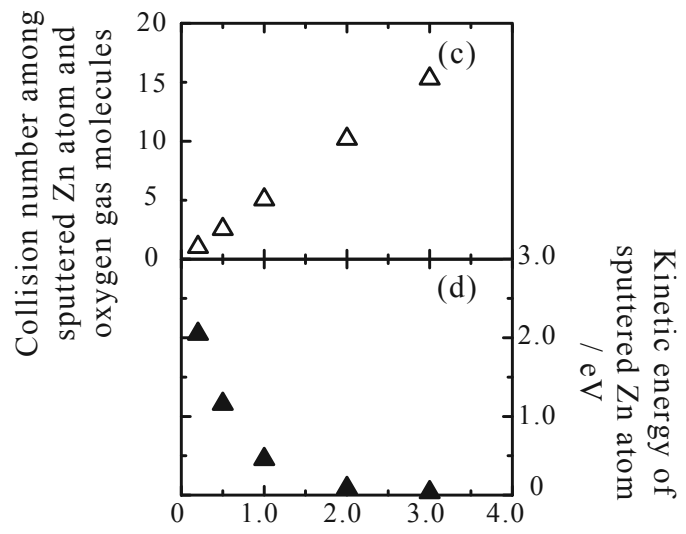

Oxygen gas pressure / $\mathrm{Pa}$

Fig. 5. (a) Collision number and (b) kinetic energy of oxygen negative ion and

(c) collision number and (d) kinetic energy of sputtered $\mathrm{Zn}$ atom calculated using Kevin-Meyer's equation.

respectively. The estimated collision number and kinetic energies of oxygen negative ion and sputtered $\mathrm{Zn}$ atom are shown as a function of oxygen gas pressure in Fig. 5. Figure 5 indicates that the collision number decreased with the decrease in the oxygen gas pressure, on the other hand, the kinetic energies significantly increased. This theoretical calculation supports that the drastic increase in the kinetic energy of these particles is caused by the decrease of the collision number; in consequence, the microstructure the $\mathrm{ZnO}$ thin films deposited in low oxygen gas pressure should be influenced. It can be considered that the oxygen negative ions have enough kinetic energy to impact on the $\mathrm{ZnO}$ thin film in low oxygen gas pressure; therefore, oxygen negative ions can cause the atomic peening effect [18], which results in the compressive distortion and high packing density of $\mathrm{ZnO}$ thin films. Besides, the oxygen negative ions can be accelerated by cathode voltage with the direction vertical to substrate surface; hence, the $\mathrm{ZnO}$ thin films with preferential crystal orientation vertical to substrate surface were grown when they were deposited in low oxygen gas pressure. Furthermore, it can be said that high kinetic energy of sputtered $\mathrm{Zn}$ atoms in low oxygen gas pressure can lead 
to an increase of migration of $\mathrm{Zn}$ atoms on substrate surface during thin film growth; as a result, the $\mathrm{ZnO}$ thin films with high packing density and smooth surface can be obtained.

\subsection{Double-layered low-e coatings}

Figure 6 shows the resistivity change of the $\mathrm{Ag}$ thin films used in the double-layered low-e coatings against

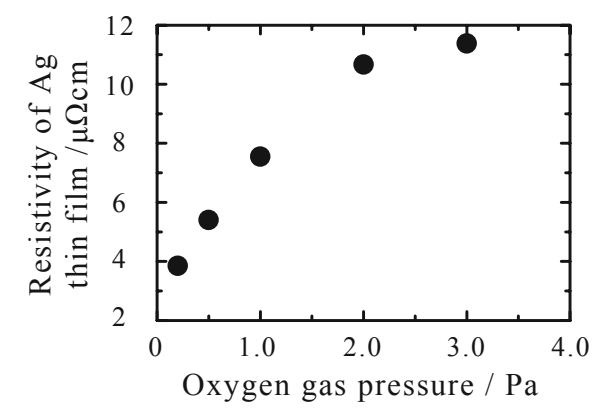

Fig. 6. Dependence of resistivity of Ag thin films used in low-e coatings on oxygen gas pressure during $\mathrm{ZnO}$ deposition.
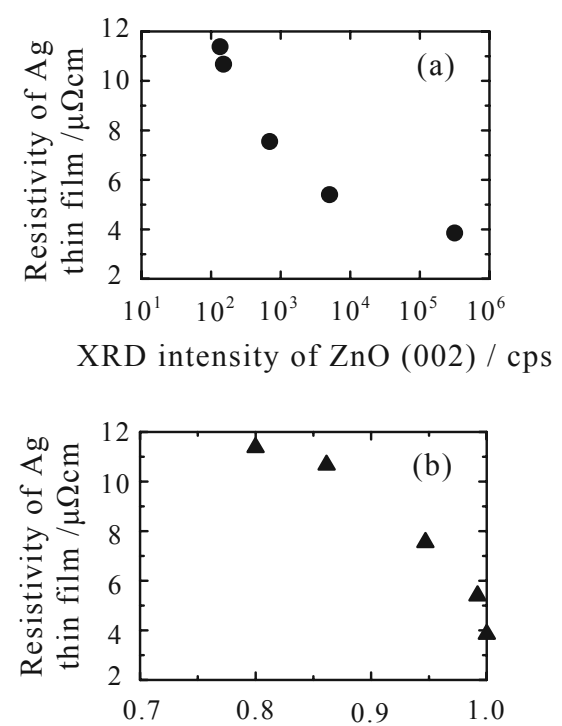

Relative packing density of $\mathrm{ZnO}$ thin film

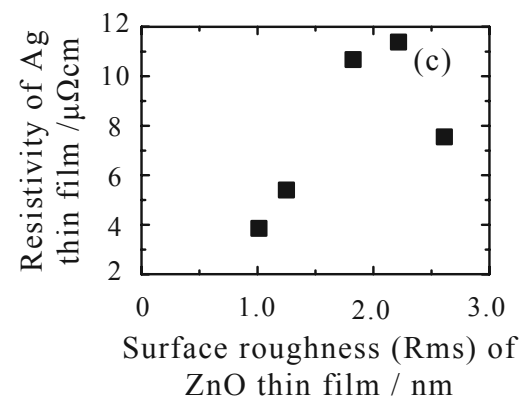

Fig. 7. Change in resistivity of $\mathrm{Ag}$ thin films used in double-layered low-e coatings as a function of (a) XRD intensity, (b) relative packing density and (c) surface roughness of $\mathrm{ZnO}$ under layer. oxygen gas pressure during the $\mathrm{ZnO}$ under layer deposition. It can be seen from Fig. 6 that the resistivity of $\mathrm{Ag}$ thin films clearly decreased when the $\mathrm{ZnO}$ under layers were deposited under lower oxygen gas pressure. This variation of the resistivity of $\mathrm{Ag}$ thin films should be due to the microstructure change of $\mathrm{ZnO}$ under layers.

Figure 7 shows the dependence of the Ag thin film resistivity used in the double-layered low-e coating on the microstructure parameter of $\mathrm{ZnO}$ under layers, such as the XRD intensity, packing density and surface roughness of $\mathrm{ZnO}$ under layers. Figure 7 indicates that the resistivity of $\mathrm{Ag}$ thin films decreased when the $\mathrm{ZnO}$ under layers exhibited high XRD intensity, high packing density and smooth surface roughness. We have already reported on the basis of the XRD measurement results that the Ag thin films were highly crystallized on $\mathrm{ZnO}$ under layers [12]. It can be considered that the heteroepitaxial-like growth of $\mathrm{Ag}$ thin films was preferentially promoted when they were deposited on the $\mathrm{ZnO}$ thin films with high crystallization, high packing density and smooth surface, in consequent, the resistivity of $\mathrm{Ag}$ thin films should decrease.

\section{SUMMARY}

The microstructures of $\mathrm{ZnO}$ thin films were investigated as a function of oxygen gas pressure during deposition. The following results were obtained:

(1) When low oxygen gas pressure was applied, the $\mathrm{ZnO}$ thin films with preferential orientation and compressive distortion were obtained.

(2) The $\mathrm{ZnO}$ thin films deposited in low oxygen gas pressure exhibited high packing density and smooth roughness.

It can be concluded that these microstructure changes of $\mathrm{ZnO}$ thin films should come from the effects of oxygen negative ions and sputtered $\mathrm{Zn}$ atoms with high kinetic energy during the sputtering deposition; besides, it was found that the kinetic energy of these particles strongly depends on the collision frequency with oxygen gas molecules. Furthermore, the resistivity of double-layered low-e coatings were investigated and it was found that the Ag thin films with low resistivity were obtained using $\mathrm{ZnO}$ thin films with preferential orientation of $\mathrm{ZnO}$ (002) lattice plane, high packing density and smooth surface.

\section{REFERENCES}

[1] R. J. Hill, S. J. Nadel, "Coated Glass Applications and Markets", BOC Coated Tech., (1999) pp. 68-86.

[2] T. Otsuki, S. Omi and H. Nakashima, J. Jpn. Soc. Infrared Sci. Tech., 7, 125-31 (1997) [in Japanese].

[3] F. Simonis, M. V. Leij and C. J. Hoogendoom, Solar Energy Mat., 1, 221-31 (1979).

[4] K. Kato, H. Omoto and A. Takamatsu, Vacuum, 84, 587-91 (2009).

[5] C. Charton and M. Fahland, The $46^{\text {th }}$ annual technical conference proc. of Soc. Vac. Coaters, Sanfrancisco, USA, 190-94 (2003).

[6] S. Baba, A. Kinbara and M. Adachi, Vacuum, 42, 279-82 (1991).

[7] C. Charton and M. Fahland, Surf. Coat. Tech., 
174-175, 181-86 (2003).

[8] R. C. O'handley, D. K. Burge, S. N. Jasperson and E. J. Ashley, Surf. Sci., 50, 407-33 (1975).

[9] K. Kato, H. Omoto and A. Takamatsu, Abstract of the $50^{\text {th }}$ annual symposium of Vac. Soc. Jpn., Tokyo, Japan, 116 (2009).

[10] M. Arbab, Thin Solid Films, 381, 15-21 (2001).

[11] Y. Tsuda, H. Omoto, K. Tanaka and H. Ohsaki, Thin Solid Films, 502, 223-27 (2006).

[12] K. Kato, H. Omoto and A. Takamatsu, Vacuum, 83, 606-9 (2008).

[13] I. Kojima and B. Li, The Rigaku J., 16, 31-41 (1999).

[14] K. Ishibashi and Y. Shiokawa, Proc of the $3^{\text {rd }}$ International Symposium on Sputtering and Plasma Processes, Tokyo, Japan, 423- (1995).

[15] T. Sasabayashi, N. Ito, E. Nishimura, M. Kon, P. K. Song, K. Utsumi, A. Kaijo and Y. Shigesato, Thin Solid Films, 445, 219-23 (2003).

[16] M. Yamagishi, S. Kuriki, P. K. Song, Y. Shigesato, 442, 227-31 (2003).

[17] K. Meyer, I. K. Schuller, C. M. Faico, J. Appl. Phys., 52, 5803 (1981).

[18] J. A. Thornton, D. W. Hoffman, Thin Solid Films, 171, 5-31 (1989).

(Received February 5, 2010; Accepted February 28, 2010) 